\title{
Re: Baumgarten et al.: Vitrectomy with and without encircling band for pseudophakic retinal detachment with inferior breaks: VIPER Study Report No. 3. Graefes Arch Clin Exp Ophthalmol. 2018 Nov;256(11):2069-2073. doi: 10.1007/s00417-018-4106-6. Epub 2018 Aug 23
}

\author{
Piergiacomo Grassi $^{1}$ (D) Philip Alexander ${ }^{2}$ - Arabella V. Poulson ${ }^{2} \cdot$ Martin P. Snead $^{2}$
}

Received: 27 December 2018 /Revised: 24 January 2019 / Accepted: 9 February 2019 / Published online: 20 February 2019

(C) Springer-Verlag GmbH Germany, part of Springer Nature 2019

Dear Editor:

We read with interest the recent prospective randomized controlled multicenter trial by Baumgarten et al. which concludes that the use of an encircling band (EB) with vitrectomy in patients with uncomplicated pseudophakic retinal detachment (PRD) and inferior multiple breaks does not significantly improve primary anatomical success when compared with vitrectomy alone [1].

Although a marginally higher anatomical success rate was achieved by the addition of an EB when compared with vitrectomy alone (especially for patients with breaks between the 5:00 and 7:00 o'clock meridians), the difference was not statistically significant. However, both study arms had relatively high failure rates (primary anatomical success rate $79 \%$ for vitrectomy + EB versus $73.5 \%$ for vitrectomy alone) when compared with the previous studies referenced in their paper ( $95 \%$ primary success vitrectomy with combined EB [2], 81\% vitrectomy alone [3]).

The authors state that the EB was positioned underneath the rectus muscles and subsequently fixated in all four quadrants at the equator of the globe. Unless all the inferior retinal breaks are also located at the anatomical equator, deployment of an explant or scleral buckle in such a manner is highly

Piergiacomo Grassi

piergiacomo.grassi@addenbrookes.nhs.uk

1 Department of Ophthalmology, Addenbrooke's Hospital, Cambridge University Hospitals NHS Foundation Trust, Cambridge Biomedical Campus, Hills Road, Cambridge CB2 0QQ, UK

2 Department of Ophthalmology, Addenbrooke's Hospital, Cambridge University Hospitals NHS Foundation Trust, Cambridge Biomedical Campus, Hills Road, Cambridge CB2 0QQ, UK unlikely to confer any additional benefit over vitrectomy alone. Identification and accurate buckle localization for closure of inferior breaks are no less important than for breaks anywhere else. If an encircling buckle is being deployed, then accurate break localization and closure may dictate that this will need to be positioned on a great circle of the globe, rather than the arbitrary application to the equator.

\section{Compliance with ethical standards}

Conflict of interest The authors declare that they have no conflict of interest.

Publisher's note Springer Nature remains neutral with regard to jurisdictional claims in published maps and institutional affiliations.

\section{References}

1. Baumgarten S, Schiller P, Hellmich M, Walter P, Agostini H, Junker B, Helbig H, Lommatzsch A, Mazinani B, VIPER Study Group (2018) Vitrectomy with and without encircling band for pseudophakic retinal detachment with inferior breaks: VIPER study Report No. 3. Graefes. Arch Clin Exp Ophthalmol 256(11):20692073. https://doi.org/10.1007/s00417-018-4106-6

2. Alexander P, Ang A, Poulson A, Snead MP (2008) Scleral buckling combined with vitrectomy for the management of rhegmatogenous retinal detachment associated with inferior retinal breaks. Eye (Lond) 22(2):200-203

3. Wickham L, Connor M, Aylward GW (2004) Vitrectomy and gas for inferior break retinal detachments: are the results comparable to vitrectomy, gas, and scleral buckle? Br J Ophthalmol 88(11):13761379 